\section{Sero-prevalence of herpes simplex type 2 virus (HSV-2) and HIV infection in}

\section{Kampala, Uganda}

Edith Nakku-Joloba ${ }^{1}$, Fred Kambugu² ${ }^{2}$, Julius Wasubire ${ }^{3}$, Joshua Kimeze ${ }^{2}$, Robert Salata ${ }^{4}$ Jeffrey M. Albert ${ }^{5}$, Alfred Rimm ${ }^{6}$, Christopher Whalen

1. Makerere University College of Health Sciences, School of Public Health 2. STD Clinic/Ward 12, Mulago National Referral Hospital

3. Mbarara University of Science and Technology, Computer Science

4. Case Western reserve University, Medicine

5. Case Western Reserve University, Biostatistics

6. Case Western Reserve University, Epidemiology

7. University of Georgia, College of Public Health, Epidemiology and Biostatistics

\section{Abstract}

\section{Background:}

Prevalence of herpes simplex type 2 virus (HSV-2) is high worldwide. Previous studies in Uganda were rural or in women. We estimated age and sex-specific sero- prevalence of HSV-2 in Kampala, Uganda.

Methods: Using two-stage random sampling stratified on population density, a survey of persons 15-65 years was conducted. Type-specific serological tests for HSV-2, HSV-1(HerpeSelect2 and 1 ELISA), HIV (Rapid tests and ELISA), syphilis (RPR and TPHA) were done. Additional prevalence analysis included post-stratification weighting on the Uganda 2002 lis (RPR and TPHA) were

Census gender distribution.
Results: Among 1124 persons, HSV-2 prevalence was 58\% (95\% CI: 55, 60), HSV-1; $98 \%$ (95\% CI: 97.6, 99.1), HIV; $17.7 \%$ Results: Among 1124 persons, HSV-2 prevalence was $58 \%$ ( $95 \%$ CI: 55,60$)$, HSV-1; $98 \%$ (95\% CI: $97.6,99.1)$, HIV; $17.7 \%$
(95\% CI: $14.8,19.2$ ) and syphilis; $1.7 \%$ ( $95 \%$ CI: 1.4, 1.9). Weighted HSV-2 prevalence was $53.8 \%$ (Women; $63.8 \%$, men $43.2 \%$ ), similar to unweighted data. Weighted HIV prevalence was $20.7 \%$ in women, $8.6 \%$ in men. Of $165 \mathrm{HIV}$ infected persons, 85.4\% had HSV-2. Risk factors for HSV-2 were being a woman (OR 2.0; 95\% CI: 1.42, 2.78), age (OR 3.3;

95\% CI: 2.43, 4.53), education (OR 1.70; 95\% CI: 1.34, 2.34) and HIV (OR 4.5; 95\% CI: 2.70, 7.50).

Conclusion: Prevalence of HSV-2 and HIV was high especially in women. Syphilis was rare. Awareness of herpes was low. Interventions in young people are needed.

Keywords: HSV-2, HIV, Kampala Uganda

\section{DOI: http://dx.doi.org/10.4314/ahs.v14i4.2}

\section{Introduction} Infection with herpes simplex virus type 1 and 2 (HSV-1 Uganda were in rural settings ${ }^{7}$. At the time this study and 2) is common worldwide ${ }^{1}$.Estimates of HSV-2 was conducted, there was limited population data on prevalence in Africa are high; $78 \%$ in women and prevalence of HSV-2 infection in Uganda's urban ar$45 \%$ in men ${ }^{2}$ No vaccine exists to prevent infection. HSV-2 infection is closely correlated to and fuels the women, ${ }^{8,9}$, pregnant women and clinical trial populaHIV epidemic in sub-Saharan Africa and elsewhere ${ }^{3,4,5}$. tions ${ }^{10}$ but population estimates of HSV-2 infection in Studies to disrupt this synergy have been unsuccessful ${ }^{6}$. urban Uganda are few.

HSV-2 remains an important sexually transmitted disease (STD); inherently and because of its synergy with HIV.

\begin{tabular}{|l|}
\hline Corresponding author: \\
Edith Nakku-Joloba \\
Makerere University College of Health Sciences, \\
School of Public Health \\
edith.nakkujoloba@gmail.com
\end{tabular}

\section{Materials and Methods}

\section{Study desion and procedure}

From February 2004 to June 2004, we conducted a study evaluating the prevalence of HSV-2 among residents of Kawempe Division (one of five divsions in urban Kampala), Uganda. Using two-stage stratified random sampling weighted on population density, we randomly selected 7 of 18 parishes in Kawempe and stratified these 7 on population density. Using detailed maps of all roads in the area from the Uganda Bureau of Statistics, we numbered the mapped road junction in each parish. The road junctions were then randomly selected with replacement from a covered box as points for starting data collection each morning. The direction research assistants took was selected with replacement from a box with four directions. We approached people in every third housing unit and one consenting person was chosen without replacement in every third housing unit to enroll.

Enrolled participants were 15 to 65 years old, had lived in the area for at least two weeks, and able to give written informed consent or assent to the study.

Participants consented to HSV-2 testing but could opt out of HIV testing. Participants received pre and post test HIV counseling and if HIV positive, given referral for care to Mulago National Referral Hospital or clinic of their choice. HSV-2 positive persons with symptoms were referred to the STD clinic, reviewed and provided with episodic acyclovir treatment during the study.

Trained research assistants obtained consent from eligible persons prior to confidential interviews and blood draws. We used standardized pre-tested questionnaires to collect data on socio-demographics, sexual history, history of symptoms related to genital ulcer disease and other STDs. Return visits over weekends and evenings were conducted but did not change distribution of men enrolled.

A contact address was collected. Consenting participants provided a sample of blood $(5 \mathrm{ml})$ for laboratory testing.

We tested sera for HSV-1 and 2 using type-specific serological tests (HerpeSelect 1 and 2 ELISA.), Focus Technologies, California) ${ }^{11}$. We considered index values of 3.5 and above to indicate HSV-2 infection. We explored the 2.2 cut off and 1.1 cut off to describe potential lower limits for prevalence; the manufacturer's cut off was considered diagnostic for HSV-1 infection. HIV was tested using HIV ELISA (HIV ELISA Vironostika HIV Uni-form II Ag/Ab (BioMerieux Boxtel, Netherlands).Persons with a positive HIV ELISA test received a rapid test (Capillus HIV-1/HIV-2, Trinity Biotech, USA) for confirmation. For those with discordant results on these two tests, we performed a third rapid HIV test (Abbot Determine, Abbott Laboratories Abbott Park IL, USA) as a tie breaker. Persons testing positive on two of the tests were considered HIV infected. We tested for syphilis using the RPR Test $(\mathrm{Hu}-$ man GmbH Wiesbaden, Germany) and confirmed with TPHA (Syphilis TPHA liquid Test (Human GmbH Wiesbaden, Germany). The study was reviewed and proved by University Hospitals of Cleveland Ethial Review Board, the Joint Clinical Research Center (JCRC) Ethical Review Board and the Uganda National Council of Science and Technology.

We calculated the proportion of persons with HSV-2 infection with 95\% confidence intervals using the 3.5 cut off. We also conducted sensitivity analyses for HSV-2 prevalence with the FDA approved cut off (1.1 and above) and a 2.2 cut off suggested in an earlier paper with colleagues ${ }^{12}$. The final reported results are based on the 3.5 cut off to increase specificity ${ }^{13,14}$. We calculated weighted proportions for HSV-2 and HIV infection among women and men to mitigate potential bias due to skewed response from women $(70 \%$ in study compared to a $51 \%$ population distribution $)^{15}$. We calculated the proportion of people with HSV-1 and syphilis infection with 95\% confidence intervals. Chi-square tests, F-tests of significance and univariate logistic regression were used to assess sociodemographic factors associated with odds of HSV-2 infection. To assess confounding and interaction, we built multivariate logistic models to include factors significant at $\mathrm{p}<=0.05$ on univariate analysis. The model fit was evaluated using Hosmer-Lemeshow goodness of fit tests. As a sensitivity analysis, we repeated our regression with the HerpeSelect 2 manufacturer's cut off for positivity of 1.1 index value and the 2.2 index value but this did not appreciably change the results (data not shown). Data was analyzed using PASW 10.0 (PASW Inc, Chicago IL) and SAS version 9.1 software (SAS Institute Inc. Cary, North Carolina).

A sample size was generated for each selected stratum proportionate to population size. We calculated a sample size of 1073 persons based on an overall HSV-2 prevalence of 54\%, and for specific age groups 15-19, 25-29 and greater than 40 years from prevalence studies on HSV-2 in rural Uganda with 5\% error and after sample allocation and weighting for population density ${ }^{1617}$.

\section{Results}

We enrolled 1124 persons who provided questionnaire data and blood samples for the HSV-2 and HSV-1 antibody test. 971 persons $(85.5 \%)$ consented to HIV testing and all but $11(1 \%)$ consented to receiving HIV results. Enrolled participants included $786(70 \%)$ women and $338(30 \%)$ men. Median age was 26 years (Interquartile range [IQR] 22 to 33 years). Men and women enrolled were similar as regards age $(\mathrm{p}=0.44)$ 
The most common occupation was small business fol- education than women $(\mathrm{p}<0.001)$ and were more likely lowed by housewives (Table 1 ) to have extra marital partners $(30 \%$ vs $12 \%$ ).

Students made up $117(10.4 \%)$ and $149(13.3 \%)$ were Women were more likely to have an older sexual partne unemployed. More than half were married $(615,54.7 \%)$ and to have had earlier sexual intercourse. Only 94 perand in a stable partnership. Nearly half of participants sons (8.4\%) reported using condoms for every sex act had a primary education. Men had significantly higher in the past thirty days. Nearly half reported they used

Table 1 Unadjusted and Adjusted Models for Correlates of Prevalent HSV-2 in the Survey Population

\begin{tabular}{|c|c|c|c|c|}
\hline VARIABLE & $\overline{\mathbf{N}}$ & $\begin{array}{c}\text { HSV-2 Positive } \\
\text { n (\%) }\end{array}$ & $\begin{array}{c}\text { Unadjusted Odds } \\
(95 \% \text { Ratio } \\
(95)\end{array}$ & $\begin{array}{l}\text { Adjusted Odds } \\
\text { Ratio (95\% CI) }\end{array}$ \\
\hline 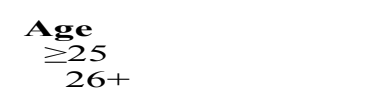 & $\begin{array}{l}546 \\
578\end{array}$ & $\begin{array}{l}233(43) \\
417(72)\end{array}$ & $\begin{array}{l}1.00(\text { Ref }) \\
3.47(2.71-4.46)\end{array}$ & $3.30(2.43-4.53) *$ \\
\hline $\begin{array}{l}\text { Age at first sex } \\
\geq 19 \text { years }\end{array}$ & 240 & $111(46)$ & 1.00 (Ref) & \\
\hline $\begin{array}{l}<19 \text { years } \\
\text { Gender }\end{array}$ & 884 & $539(61)$ & $1.82(1.36-2.42)$ & $1.07(0.85-1.36)$ \\
\hline Male & 338 & $147(43)$ & 1.00 (Ref) & \\
\hline $\begin{array}{c}\text { Female } \\
\text { Education } \\
>7 \text { years }\end{array}$ & $\begin{array}{l}786 \\
540\end{array}$ & $\begin{array}{l}503(64) \\
260(48)\end{array}$ & $\begin{array}{c}2.31(1.78-2.91) \\
1.00(\text { Ref }\end{array}$ & $2.00(1.42-2.78)^{*}$ \\
\hline $\begin{array}{l}>7 \text { years } \\
\geq 7 \text { years }\end{array}$ & $\begin{array}{l}540 \\
583\end{array}$ & $\begin{array}{l}260(48) \\
390(67)\end{array}$ & $\begin{array}{c}1.00(\text { Ref }) \\
2.17(1.71-2.77)\end{array}$ & $1.70(1.34-2.34)^{*}$ \\
\hline $\begin{array}{l}\text { Relationship Type } \\
\text { Open }\end{array}$ & 798 & $461(58)$ & 1.00 (Ref) & \\
\hline One partner & 316 & $182(58)$ & $1.1(0.76-1.29)$ & $1.05(0.69-1.55)$ \\
\hline $\begin{array}{l}\text { Duration of } \\
\text { Partnership }\end{array}$ & & & & \\
\hline $\begin{array}{l}>2 \text { years } \\
\geq 2 \text { years }\end{array}$ & $\begin{array}{l}601 \\
324\end{array}$ & $\begin{array}{l}396(66) \\
145(45)\end{array}$ & $\begin{array}{c}1.00(\text { Ref }) \\
0.42(0.32-0.55)\end{array}$ & $0.82(0.57-1.20)$ \\
\hline $\begin{array}{l}\text { Condom Use } \\
\text { High Users }\end{array}$ & 250 & 111 & 1.00 (Ref) & \\
\hline Low users & 767 & 474 & $1.93(1.4-2.64)$ & $1.34(0.97-1.96)$ \\
\hline $\begin{array}{l}\text { Hratus(n=971) } \\
\text { Negative } \\
\text { Nositive } \\
\text { Declined }\end{array}$ & $\begin{array}{l}806 \\
165 \\
153\end{array}$ & $\begin{array}{l}424(52.6) \\
141(85.4)\end{array}$ & $\begin{array}{c}1.00 \text { (Ref) } \\
5.29(3.3-8.3)\end{array}$ & $4.52(2.73-7.49)^{*}$ \\
\hline
\end{tabular}

condoms rarely in the past thirty days and $52(5 \%)$ had not used condoms in the past 30 days. Condom use was unusual with regular partners.

Of 1124 participants, 648 (58\%, 95\% CI: 55,60) tested HSV-2 positive using the HerpeSelect 3.5 cut off $(75 \%$ and $61 \%$ tested positive using the 1.1 and $2.2 \mathrm{cut}$ off respectively). Weighted analysis on gender distribu- tion did not appreciably change the overall and gender and $43.0 \%$ for men). Gender specific HSV-2 prevalence was similar in the weighted and the un-weighted data. Prevalence of HSV-2 increased with age $36 \%$ in the $15-19$ year age group to $85 \%$ in the 40 and above age group). Women had significantly higher prevalence of HSV-2 compared to men $(p<0.0001)$ and the differences increased with age (Figure 1). specific prevalence $(57.8 \%$ overall $; 64.0 \%$ for women

\section{Age Specific HSV-2 Prevalence among} Women and Men

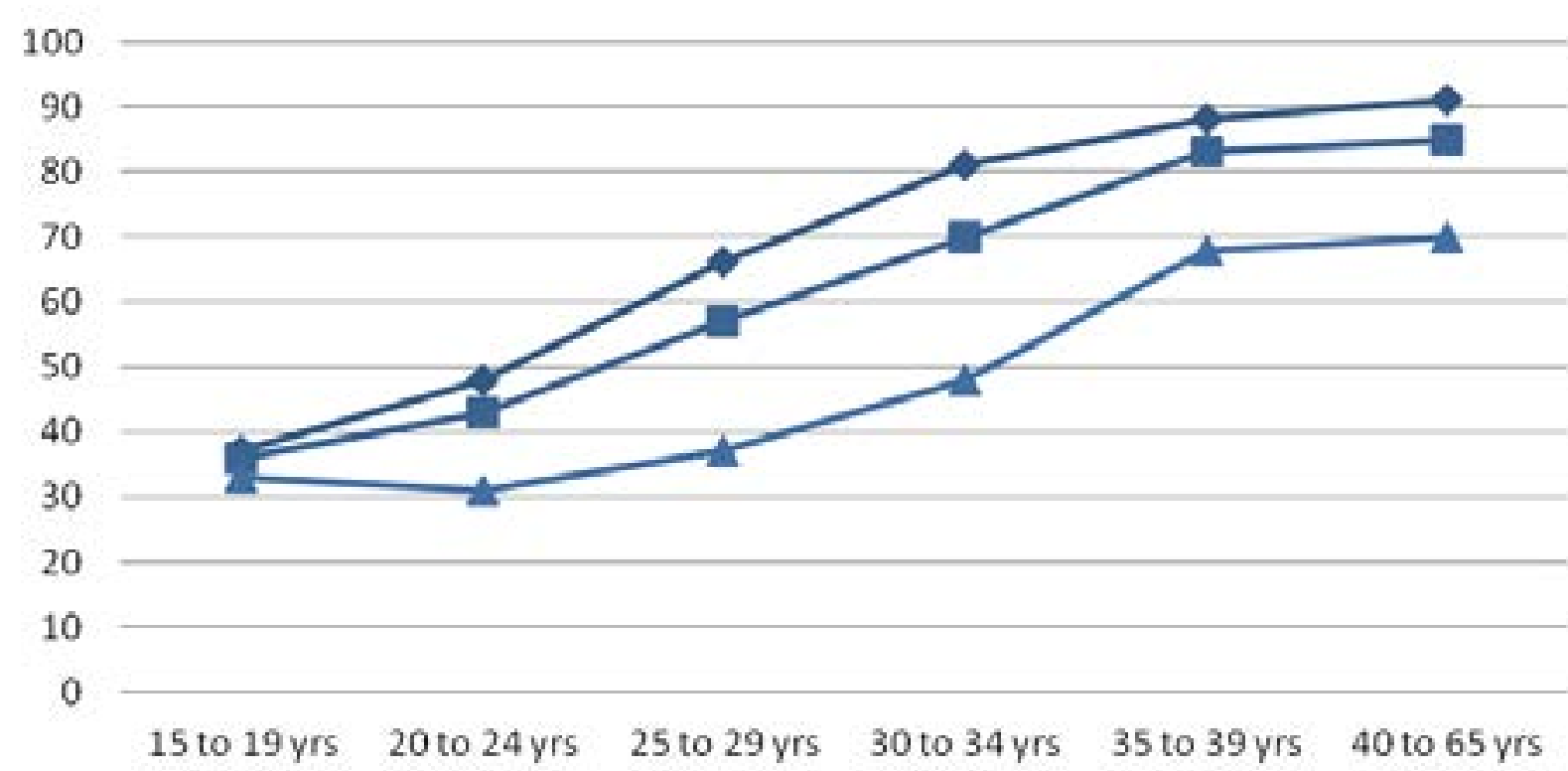

A total of 1106 persons (98 \%, 95\% CI: 97.6, 99.1) age group and HIV status, (Breslow Day Test for Hotested HSV-1 positive. Seventeen percent of people mogeneity of the Odds Ratio $\mathrm{p}=0.73$, MH COR 5.18 ; had HIV infection (95\% CI: 14.80, 19.15). Men had 95\%CI: 2.6,10.1) nor between gender and HIV status ( sionificantly lower HIV prevalence $(8.6 \%)$ than women $(22 \%),(p<0.001)$. On weighting, HIV prevalence
was $16 \%(95 \%$ CI: $15.87,16.10)$, HIV prevalence for women was $19.9 \%$ and for men $8.4 \%$, similar to the un-weighted data. Syphilis in this population was rare at $1.7 \%(95 \%$ CI: $1.40,1.90)$

On univariate analysis, women were more likely to have HSV-2 infection (OR 2.0,95\% CI 1.42-2.78) compared to men. Age of participants, age when they first had sex , years of education, condom use with regular partner and HIV status were associated with HSV-2 prevalence (Table 1).

Log odds of HSV-2 infection increased linearly with age $(\mathrm{p}<0.001)$. Among people who reported use of condoms with their regular partner, people who used condoms more often had lower odds of HSV-2 infection (OR 0.5; 95\% CI: 0.48-0.64). There was no statistical evidence for two way interaction between gender and age group; (Breslow Day Test for Homogeneity of the Odds Ratio $\mathrm{p}=0.11$, Mantel-Haenszl Common Odds Ratio (MH COR 3.43 ; 95\% CI: 2.55, 4.62); between
Breslow Day Test for Homogeneity of the Odds Ratio $\mathrm{p}=0.33$, (MH COR $5.59 ; 95 \%$ CI

$2.88,10.81)$.

In the adjusted multivariable logistic model (Table 1), risk factors associated with HSV-2 infection were gender (OR 2.0; 95\% CI: 1.42, 2.78), being older than 25 years (OR 3.3; 95\% CI: 2.43, 4.53), education level (OR 1.70; 95\% CI: 1.34, 2.34) for persons with less than 7 years of education and HIV status (OR 4.5; 95\% CI:2.70, 7.50). 141(14.5\%) of all sample study participants were dually infected with HSV-2 and HIV. Of 165 persons infected with HIV, 85.4\% also had HSV-2 infection. In contrast, among the HIV negative persons $52.6 \%$ (424) had HSV-2 infection. In total, 558 persons reported a history of genital ulcers.

Of the 648 people who tested HSV-2 positive, 301 $(46.5 \%)$ reported history of ulcers and thought those ulcers were due to syphilis infection. However in this sample, only 19 people out of the $1124(1.69 \%)$ tested positive for syphilis. Of these $15(79 \%)$ had HSV-2 infection. 

high prevalence of HSV-2 infection (58\%), demonstrating a high burden of genital herpes in urban Uganda.

Prevalence among women 20 years and above was significantly higher than in men. However, there was similarity in HSV-2 prevalence in the 15 to 19 year age group for men and women. Prevalent HIV infection was high over all but higher among women. Syphilis was rare bu many with history of genital ulcers who tested HSV 2 positive, reported they thought the ulcers were due to syphilis and only rarely due to herpes. Risk factor for prevalent HSV-2 infection included being a woman, older age, low condom use, younger age at first sex and presence of HIV infection similar to earlier studies. These associations were significant on univariate and multivariable analyses, again similar to several studies

The report shows a high rate of HSV-2 co-infection among HIV infected persons.

To our knowledge, this is one of the few population studies on HSV-2 prevalence and associated risk factors in urban Uganda. Prevalence of HSV-2 was higher than in earlier rural population studies in Uganda (Rakai, Masaka) ${ }^{19,20}$. The Uganda national sero-behavioral surve done in 2004-5 showed similar prevalence of HSV-2 ${ }^{21}$ with a different a serological test and low syphilis. Similar HSV-2 prevalence (30-80\%) has been reported from other urban sub-Saharan locations. For example, in urban Zimbabwe HSV-2 prevalence was $68 \%$ and in Ndola, Zambia $55 \%{ }^{22}$. In contrast, population-based studies found substantially lower prevalence in Europe ${ }^{23}$ and Australia. ${ }^{24}$. The recent NHANES (2005-2008) survey in the US found prevalence of $16.2 \%$. However, the HSV-2 prevalence among non-Hispanic African Americans in that survey was comparable to our study,
at $56 \% .{ }^{25}$ Similarly high prevalence $(54 \%)$ has been noted in Haiti.

In our study, as in Haiti , Africa and Europe ${ }^{16,26,19}$, we found that women aged 20 and above had higher prevalent HSV-2 infection. This high prevalence in women is similar to studies in Uganda where prevalence was about $50 \%{ }^{21}$ in the national survey, $86 \%$ and $62 \%$ in clinic sample of HIV-positive and HIV- negative pregnant women respectively ${ }^{9}$. Gender specific differences in HSV-2 infection have also been seen in Kenya and the Gambia ${ }^{22,27,28}$. Consistent data from many populations in sub Saharan Africa shows higher prevalence of
HIV infection in women compared to men in population samples ${ }^{29,30,31}$. Multivariable risk factors for prevalent HSV-2 infection (women, older age, low condom use, younger age at first sex and presence of HIV infection were similar to earlier studies. ${ }^{18}$ Co-infection with HSV-2 and HIV has been documented in several studie $^{22,34}$. Kirakoya in addition to these risk factors, found use bacterial vaginosis (BV) and incident HSV-2 infection 35 in women.

The gender differences for HSV-2 and HIV may be explained in part by the biological susceptibility of the female genital tract which makes women vulnerable to sexually transmitted diseases. Women may be vulnerable to HIV and HSV-2 due to innate biological fac tors. The highly prevalent herpes among women may contribute too ${ }^{32}$, as does the more efficient transmission of HIV from men to women. Probable increment in susceptibility of genital mucosa in the presence of hormonal contraceptives in women due to reduction in normal bacteria in the tract has been proposed as an explanation for the association between HSV-2 infection and contraceptive use ${ }^{33}$ though hormonal contraceptive use may be a proxy for unprotected sexual intercourse. The documented synergy of HIV-1 and HSV-2 infection; and of contraceptives and HSV-2 infection in women in Africa, will need further exploration. Regarding HSV-2/HIV co-infection, recent studies have shown that treatment with acyclovir for HSV-2 did not have an impact on reduction of HIV transmission. ${ }^{6,36}$. A study by Zhu and colleagues showed that persistence and enrichment of HIV receptor cells (CD-4 T-cells) may create a good environment for the entry, attachment and dissemination of HIV in persons who have HSV-2 infection with or without ulceration. HSV-2 remains important for HIV transmission.

Socioeconomic factors may contribute to the gender disparity in prevalence of HSV-2. Education level, usually lower in women in developing nations may be a co- factor to explain the higher prevalence in women ${ }^{38}$ as number of years in school is associated with safer sexual practices.

The higher prevalence in women too, may be enhanced by disparities in access to sexual health care of women in low income populations where cultural and social factors have been documented to influence access to care. Polygamy, increased number of sexual partners especially among men, older age of partners coupled with early sexual debut by girls as shown in this study may further contribute to the higher risk for HSV-2 and resultant prevalence in women.

Western blot. However, the higher cut off point

\section{Conclusion}

We reported high prevalence of HSV-2 and of HIV There was a similarity in HSV-2 prevalence in the 15-19 infection, especially among women in urban Kampala. year categories for men and women, implying that this HSV-2 infection was associated with being a woman, gender disparity in prevalence of HSV-2 only emerges low condom use, early sexual debut. Prevalence inin the female age groups with time. The study found creased with age. Combined with a lack of self awarelower HSV-2 prevalence younger age groups, notably ness among those that they may be HSV-2 infected and similar in boys and girls. The lower, similar prevalence with the high HIV prevalence, probability of HSV-2 in boys and girls 15-19 years of age may present a win- transmission is high yet tests for herpes are limited to dow of opportunity to prevent herpes infection onset in an age cohort in this population. Targeting younger boys and girls for prevention of herpes could prevent new infections and enable potential control ${ }^{39}$ and reduce the upward trend of HSV-2 prevalence. The nearly universal HSV-2 infection in the above 40 age group and the reported older of partner for young girls in this study, a phenomenon earlier documented in sub Saharan Africa ${ }^{40}$, makes transmission likely to younger girls from older men. In turn, studies show younger girls also make sexual partnerships with younger boys ${ }^{40,41}$ with resultant transmission into their peer group.

Low prevalence of syphilis in recent years has been documented elsewhere in Africa ${ }^{42}$ and may be a result of the intensive campaigns for treatment of bacterial STDs.. We found little self-awareness of genital herpes and an overwhelmingly inaccurate perception of etioogy of genital ulcer disease in this population. Education on the high prevalence of HSV-2 as opposed to syphilis and HSV-2's atypical presentation for health workers and the population will be important to addres this schism. Screening for HSV-2 is the best option but serological tests for genital herpes are still expensive. Community education may be of most benefit.

An earlier paper published with colleagues, comparing different cut-offs for the HerpeSelect2, suggests the use of a 2.2 cut off $^{12}$. However, this report uses the higher 3.5 cut off. The higher cut-off increases specificity for the HerpeSelect 2 ELISA. ${ }^{14,43,44}$

\section{Limitations}

Our study was limited in that distribution was skewed to women, despite return visits to increase men participation. We report a closely similar overall prevalence for the weighted analysis (weighted on 2002 Uganda census population distribution) for men and women. Anoth er study limitation was the absence of a confirmatory research settings in this community.

Health education on HSV-2 for health workers and the public is needed. A window of opportunity for prevention exists among the younger age groups. Behavioral interventions, especially in young women to delay sexudebut, reduce number of lifetime sexual partners and to increase consistent correct condom use could reduce HSV-2 incidence. The synergistic relationship between HSV-2, HIV and needs further exploration. The reasons underlying the divergence in gender specific prevalence with age, including contraception use also need further study. Cheaper, rapid tests for herpes simplex type 2 are needed. Since unaware, untested HSV-2 infected persons may be mixing freely within the population, the genital herpes epidemic may continue to grow in the absence of strong public health measures. Targeted public health engagement regarding HSV-2 in this population is crucial.

\section{Acknowledgmen}

This work was supported by the National Institutes of Health, Fogarty International Center and the National Institutes of Health Office of Women's Health of the United States under the Global Research Initiative Program for New Foreign Investigators (GRIP) Grant Number TW006672-01 and the Government of Uganda, Ministry of Health.

\section{References}

1. Patnaik P, Herrero R, Morrow RA, et al. Type-specific seroprevalence of herpes simplex virus type 2 and associated risk factors in middle-aged women from 6 countries: the IARC multicentric study. Sex Transm Dis. Dec 2007;34(12):1019-1024.

2. Looker KJ, Garnett GP, Schmid GP. An estimate of the global prevalence and incidence of herpes simplex virus type 2 infection. Bull World Health Organ. Oct 2008;86(10):805-812, A. 
3. Wald A, Link K. Risk of human immunodeficiency virus infection in herpes simplex virus type 2-seropositive persons: a meta-analysis. J Infect Dis. Jan 1 2002;185(1):45-52.

4. Cowan FM, Humphrey JH, Ntozini R, Mutasa K, Morrow R, Iliff P. Maternal Herpes simplex virus type 2 infection, syphilis and risk of intra-partum transmission of HIV-1: results of a case control study. AIDS Jan 11 2008;22(2):193-201.

5. Glynn JR, Biraro S, Weiss HA. Herpes simplex virus type 2: a key role in HIV incidence. AIDS. Jul 31 2009;23(12):1595-1598.

6. Celum C, Wald A, Lingappa JR, et al. Acyclovir and transmission of HIV-1 from persons infected with HIV1 and HSV-2. N EnglJ Med. Feb 4 2010;362(5):427-439. 7. Tobian AA, Charvat B, Ssempijja V, et al. Factors associated with the prevalence and incidence of herpes simplex virus type 2 infection among men in Rakai, Uganda. J Infect Dis. Apr 1 2009;199(7):945-949.

8. Vandepitte J, Bukenya J, Weiss HA, et al. HIV and other sexually transmitted infections in a cohort of women involved in high-risk sexual behavior in Kampala, Uganda. Sex Transm Dis. Apr 2011;38(4):316-323. 9. Nakubulwa S, Mirembe FM, Kaye DK, KadduMulindwa D. Association between HSV-2 and HIV serostatus in pregnant women of known HIV serostatus attending Mulago hospital antenatal clinic, Kampala, Uganda. J Infect Dev Ctries. 2009;3(10):803-806.

10. Mujugira A, Magaret AS, Baeten JM, Celum C, Lingappa J. Risk Factors for HSV-2 Infection among Sexual Partners of HSV-2/HIV-1 Co-Infected Persons. BMC Res Notes. 2011;4:64

11. Ashley Morrow R. Performance and Use of HSV typespecific serology test kits. Herpes. July 2002 2002;9(2):38-45. 12. Lingappa J, Nakku-Joloba E, Magaret A, et al. Sensitivity and specificity of herpes simplex virus-2 serological assays among HIV-infected and uninfected urban Ugandans. Int J STD AIDS. Sep 2010;21(9):611-616.

13. Laeyendecker O, Henson C, Gray RH, et al. Performance of a commercial, type-specific enzyme-linked immunosorbent assay for detection of herpes simplex virus type 2-specific antibodies in Ugandans. J Clin Microbiol. Apr 2004;42(4):1794-1796.

14. Mujugira A, Morrow RA, Celum C, et al. Performance of the Focus HerpeSelect-2 enzyme immunoassay for the detection of herpes simplex virus type 2 antibodies in seven African countries. Sex Transm Infect. Apr 2011;87(3):238-241

15. The 2002 Uganda Population and Housing Censu

,Population Size and Distribution, October 2006, Kam- a, Uganda: Uganda Burean of Statistics;2006. G. Dobbins, and J. A. Whitworth. Seroprevalence an incidence of genital ulcer infections in a rural Ugandan population. Sex Transm Infect 1999;75:98-102.

17. Wawer MJ, Eng SM, Serwadda D, et al. Prevalence of Kaposi sarcoma-associated herpesvirus compared with selected sexually transmitted diseases in adolescents and young adults in rural Rakai District, Uganda. Sex Transm Dis. Feb 2001;28(2):77-81.

18. Tassiopoulos KK SGr, Sam N, Kiwelu I, Shao , Ao TT, Essex M, Coplan P, Rosenberg Z, Hughes M, Kapiga S. Predictors of herpes simplex virus type 2 prevalence and incidence among bar and hotel workers in Moshi, Tanzania. J Infect Dis. Feb 15 2007;4(195):493 501.

19. Kamali A, Nunn AJ, Mulder DW, Van Dyck E, Dobbins JG, Whitworth JA. Seroprevalence and incidence of genital ulcer infections in a rural Ugandan population. Sex Transm Infect. 1999;75(2):98-102.

20. Wagner HU, Van Dyck E, Roggen E, et al. Seroprevalence and incidence of sexually transmitted diseases in a rural Ugandan population. Int J STD AIDS. 1994;5(5):332-337.

21. Macro. MUaO. Uganda HIV/AIDS Sero Behavioral Survey 2004-2005. Calverton, Maryland, USA: Ministry of Health (MOH) [Uganda] and ORC Macro.; 2006 2006.

22. Weiss HA, Buve A, Robinson NJ, et al. The epidemiology of HSV-2 infection and its association with HIV infection in four urban African populations. AIDS. Aug 2001;15 Suppl 4:S97-108.

23. Smith JS RM, Trzcinska A, Pimenta JM, Litwinska B, Siennicka J. Type specific seroprevalence of HSV1 and HSV-2 in four geographical regions of Poland. Sexually Transmitted Infections. April 2006 82(2):159-163. 24. Cunningham AL, Taylor R, Taylor J, Marks C, Shaw J, Mindel A. Prevalence of infection with herpes simplex virus types 1 and 2 in Australia: a nationwide population based survey. Sex Transm Infect. Apr 2006:82(2):164-168. rus Type 2 Among Persons Aged 14-49 Years-Unite States, 2005-2008. JAMA. 2010;304 (8):849-850.

26. H Papadogeorgakis MD PhD CCP, A Katsambas MD, J M Pimenta P, C Avdeliodi MD , T Kotrotsou MD, E Frangoulis MD PhD and J S Smith PhD MPH. Herpes simplex virus seroprevalence among children, adolescents and adults in Greece. International Journal of STD and AIDS. 2008;19(4):272-278.

27. Walraven G, Scherf C, West B, et al. The burden of reproductive-organ disease in rural women in The Gambia, West Africa. Lancet. Apr 14 2001;357(9263):1161 1167.

28. Smith JS, Robinson NJ. Age-specific prevalence of infection with herpes simplex virus types 2 and 1: a global review. J Infect Dis. Oct 15 2002;186 Suppl 1:S328.

29. Barongo LR, Borgdorff MW, Mosha FF, et al. The epidemiology of HIV-1 infection in urban areas, roadside settlements and rural villages in Mwanza Region, Tanzania. AIDS Dec 1992;6(12):1521-1528.

30. Quinn TC, Overbaugh J. HIV/AIDS in women: an expanding epidemic. Science. Jun 102005;308(5728):1582 1583

31. Glynn JR, Carael M, Buve A, Musonda RM, Kahindo M. HIV risk in relation to marriage in areas with high prevalence of HIV infection. I Acquir Immune Defic Syndr. Aug 1 2003;33(4):526-535.

32. Glynn JR, Carael M, Auvert B, et al. Why do youn women bave a much bigher prevalence of HIV than young men? A study in Kisumu, Kenya and Ndola, Zambia. AIDS. Aug 2001;15 Suppl 4:S51-60.

33. Shust GF, Cho S, Kim M, et al. Female genital trac secretions inhibit herpes simplex virus infection: correlation with soluble mucosal immune mediators and impact of hormonal contraception. Am J Reprod Immunol. Feb 2010;63(2):110-119.

34. Ngo TD, Laeyendecker O, Li C, et al. Herpes simplex virus type 2 infection among commercial sex workers in Kunming, Yunnan Province, China. Int I STD AIDS. Oct 2008;19(10):694-697.

35. Kirakoya-Samadoulougou F, Nagot N, Defer MC, et al. Epidemiology of herpes simplex virus type 2 infection in rural and urban Burkina Faso. Sex Transm Dis. Feb 2011;38(2):117-123.

36. Celum C, Wald A, Hughes J, et al. Effect of aciclovir on HIV-1 acquisition in herpes simplex virus ropositive women and men who have sex with men: randomised, double-blind, placebo-controlled trial. Lancet. Jun 21 2008;371(9630):2109-2119.

37. Zhu J, Hladik F, Woodward A, et al. Persistence of HIV-1 receptor-positive cells after HSV-2 reactivation is a potential mechanism for increased HIV-1 acquisition. Nat Med. Aug 2009;15(8):886-892.

38. Lagarde E, Carael M, Glynn JR, et al. Educational level is associated with condom use within non-spousal partnerships in four cities of sub-Saharan Africa. AIDS Jul 27 2001;15(11):1399-1408.

39. Kenyon C, Colebunders R, Hens N. Determinants of generalized herpes simplex virus-2 epidemics: the role of sexual partner concurrency. Int J STD AIDS. May 2013;24(5):375-382.

40. Kuate-Defo B. Young people's relationships with sugar daddies and sugar mummies: what do we know and what do we need to know? Afr I Reprod Health. Aug 2004;8(2):13-37.

41. Luke N. Confronting the 'sugar daddy' stereotype: age and economic asymmetries and risky sexual behavior in urban Kenya. Int Fam Plan Perspect. Mar 2005;31(1):6-14.

42. Swai RO, Somi GG, Matee MI, et al. Surveillance of HIV and syphilis infections among antenatal clinic attendees in Tanzania-2003/2004. BMC Public Health. 2006;6:91.

43. Biraro S, Mavaud P, Morrow RA, Grosskurth H, Weiss HA. Performance of commercial herpes simplex virus type-2 antibody tests using serum samples from Sub-Saharan Africa: a systematic review and meta-analysis. Sex Transm Dis. Feb 2011;38(2):140-147.

44. Delany-Moretlwe S, Jentsch U, Weiss H, et al. Comparison of focus HerpesSelect and Kalon HSV-2 gG2 ELISA serological assays to detect herpes simplex virus type 2 antibodies in a South African population. Sex Transm Infect. Feb 2010;86(1):46-50. 